\title{
Nordihydroguaiaretic acid inhibits growth of cervical cancer SiHa cells by up-regulating p21
}

\author{
PENG GAO, FEI ZHAI, LEI GUAN and JIE ZHENG \\ Department of Pathology and Pathophysiology, School of Medical Science, \\ Southeast University, Nanjing, Jiangsu 210009, P.R. China
}

Received July 30, 2010; Accepted October 15, 2010

DOI: $10.3892 / \mathrm{ol} .2010 .205$

\begin{abstract}
Nordihydroguaiaretic acid (NDGA) and its derivatives possess anti-cancer effects on various types of cancer via the induction of apoptosis or cell cycle arrest. This study proved that NDGA inhibited cervical cancer SiHa cell growth and induced cell cycle arrest at the $\mathrm{G}_{1}$ phase, which may be a consequence of cell cycle kinase inhibitor p21 induction. NDGA promoted acetylation of histone $\mathrm{H} 3$ in total and p21 gene-associated chromatin. This effect is gene selective, since NDGA has no impact on the p27 gene. NDGA also inhibited HPV-16 E6 gene transcription, which in turn resulted in the restoration of $\mathrm{p} 53$ protein levels. The silencing mediator for retinoid and thyroid hormone receptors (SMRT) is a key component of the HDAC3-HDAC4-N-CoR/SMRT complex. We found that NDGA significantly inhibited the transcription of SMRT, which, together with p53, may aid in the detection of the increase of histone $\mathrm{H} 3$ acetylation within the p21 gene. Our results suggest that NDGA induces p21 transcription by selectively elevating histone $\mathrm{H} 3$ acetylation associated with p21 gene and p53 protein levels via the inhibition of HPV-16 E6 expression.
\end{abstract}

\section{Introduction}

Nordihydroguaiaretic acid (NDGA) is a non-specific inhibitor of lipoxygenase. NDGA and its derivatives exhibit anti-cancer effect on various types of cancer, including cervical cancer (1-3). High-risk human papillomavirus (HPV) infection is strongly associated with cervical cancer. The persistent expression of HPV oncogenes E6 and E7 is crucial for the induction and maintenance of malignant phenotypes (4). HPV E6 and E7 are well-known for their ability to inhibit the activity of tumor suppressors p53 and pRb, respectively

Correspondence to: Dr Jie Zheng, Department of Pathology and Pathophysiology, School of Medical Science, Southeast University, Nanjing, Jiangsu 210009, P.R. China

E-mail: jiezheng54@126.com

Key words: nordihydroguaiaretic acid, cervical cancer, histone acetylation, p21, p53
(5). Studies have shown that derivatives of NDGA inhibit the growth of cervical cancer cells by stabilizing p53 as a result of down-regulated E6 expression, which may be partially responsible for apoptosis induction or cell cycle arrest at the $\mathrm{G}_{1}$ phase found in NDGA-treated cells $(1,6)$.

p21 is a key mediator of $G_{1} / S$ transition, the expression of which is frequently absent or at low levels in cervical cancer (7), and the restoration of $\mathrm{p} 21$ expression suppresses the growth of cervical cancer cells $(8,9)$. It is known that regulation of p21 expression occurs primarily at the transcription level in p53-dependent or p53-independent manners (10) and acetylation of histone $\mathrm{H} 3$ within the p21 promoter is also a key event for effective p21 transcription $(11,12)$. With respect to cervical cancer, the results of certain studies showed that the p53 state is correlated with p21 expression (13) and that restoration of $\mathrm{p} 53$ function, either by RNAi or drug treatment against HPV E6, induces p21 expression $(14,15)$.

This study aimed to investigate the effect of NDGA on the growth and p21 expression of cervical cancer SiHa cells. Moreover, the effect of NDGA on levels of histone H3 acetylation, p53 protein and other factors was investigated in order to determine the mechanism by which NDGA regulated the p21 gene expression.

\section{Materials and methods}

Cell line. The human cervical cancer cell line SiHa was obtained from the Cell Bank of Type Culture Collection of the Chinese Academy of Sciences (Shanghai Institute of Cell Biology, Chinese Academy of Sciences, China), cultured in Dulbecco's modified Eagle's medium (DMEM; $4.5 \mathrm{~g} / 1$ glucose; Invitrogen, Grand Island, NY, USA) supplemented with 10\% fetal bovine serum, $100 \mathrm{U} / \mathrm{ml}$ penicillin and $100 \mu \mathrm{g} / \mathrm{ml}$ streptomycin in a $5 \% \mathrm{CO}_{2}$ incubator at $37^{\circ} \mathrm{C}$.

Reagents. NDGA (Sigma-Aldrich, St. Louis, MO, USA) was dissolved in dimethyl sulfoxide (DMSO) and the stock solution was diluted to the required concentrations in DMEM prior to being added to the cell culture medium. Final DMSO concentrations were $\leq 0.2 \%$. Antibodies against Ac-Histone $\mathrm{H} 3$ (Lys 9/14) and $\beta$-actin were purchased from Santa Cruz Biotechnology, Inc. (Santa Cruz, CA, USA). Antibodies against p53 were purchased from Signalway Antibody (Pearland, TX, USA). All other chemicals were of reagent grade. 
Table I. Primer sequences for RT-PCR.

\begin{tabular}{lllrr}
\hline Gene & \multicolumn{1}{c}{ Sense primer (5'-3') } & \multicolumn{1}{c}{ Anti-sense primer (5'-3') } & Tm (cycles) & Size (bp) \\
\hline p21 & TAGCAGCGGAACAAGGAGTCAG & CAGTCTAGGTGGAGAAACGGG & $56(30)$ & 263 \\
SMRT & GGAATCACGCTCGGAAACAATG & GGCGGTCTTTGTACAACCTTCA & $58(30)$ & 420 \\
GAPDH & ACCACAGTCCATGCCATCAC & TCCACCACCCTGTTGCTGTA & $56(30)$ & 450 \\
\hline
\end{tabular}

Tm, melting temperature.

Cell proliferation assay. Cell proliferation was measured by the MTT assay. SiHa cells were seeded into 96-well culture plates at $5 \times 10^{3}$ cells per well. Each group consisted of six parallel wells and was subsequently treated with various concentrations of NDGA for 24, 48 and $72 \mathrm{~h}$. The control cells were treated with $2 \%$ DMSO in culture medium. Following treatment, the cells were incubated with MTT reagent $(0.5 \mathrm{mg} /$ $\mathrm{ml})$ at $37^{\circ} \mathrm{C}$ for $4 \mathrm{~h}$. The resulting formazan crystals were solubilized by adding $150 \mu \mathrm{l}$ DMSO to each well. The optical density (OD) at $492 \mathrm{~nm}$ was measured and cell viability was determined using the formula: cell viability $(\%)=($ absorbance of the treated wells - absorbance of the blank control wells)/ (absorbance of the negative control wells - absorbance of the blank control wells) x 100\%. The MTT experiments were repeated at least three times.

Flow cytometry analysis. The cell cycle was analyzed using flow cytometry. Briefly, cells $\left(1 \times 10^{6}\right)$ were collected and washed twice in phosphate-buffered saline (PBS), then fixed in $70 \%$ alcohol for $30 \mathrm{~min}$ at $4^{\circ} \mathrm{C}$. After being washed in cold PBS three times, the cells were resuspended in $1 \mathrm{ml}$ of PBS solution with $40 \mu \mathrm{g}$ of propidium iodide (Sigma) and $100 \mu \mathrm{g}$ of RNase A (Sigma) for $30 \mathrm{~min}$ at $37^{\circ} \mathrm{C}$. The samples were then analyzed for their DNA content by fluorescence activated cell sorting (BD Immunocytometry Systems, San Jose, CA, USA). Each experiment was repeated at least three times.

Reverse transcriptase -polymerase chain reaction (RT-PCR). Total RNA was isolated from cells using RNAiso Plus (Takara, Japan) and reverse-transcribed using a reverse transcription system (Promega, Madison, WI, USA) according to the manufacturer's instructions. PCR amplification of different genes was performed using Easy Taq DNA Polymerase (TransGen Biotech, China). Table I shows the primer sequences used for RT-PCR and the product sizes. GAPDH served as an internal control. The optimal reaction conditions for PCR were determined for each primer pair. Denaturation was at $94^{\circ} \mathrm{C}$ for 40 sec and annealing at $56^{\circ} \mathrm{C}$ for $40 \mathrm{sec}$, followed by elongation at $72^{\circ} \mathrm{C}$ for $40 \mathrm{sec}$. PCR products were analyzed by $1.5 \%$ agarose/ ethidium bromide gel electrophoresis. OD values of mRNA were analyzed with Pro-Gel 4.0 Software and GAPDH was used to normalize mRNA. Each experiment was repeated at least three times.

Western blot analysis. Nuclear extracts from SiHa cells were prepared using a Nuclear Protein Extraction kit (BestBio, China). The protein concentrations were determined using an Enhanced BCA Protein Assay kit (Beyotime, China). The nuclear proteins $(40 \mu \mathrm{g})$ were fractionated using sodium dodecyl sulfate-10\% polyacrylamide gels for electrophoresis (SDS-PAGE) and the proteins were transferred onto a polyvinylidene fluoride (PVDF) membrane. The membrane was blocked at room temperature for $4 \mathrm{~h}$ with $5 \%$ bovine serum albumin in Tris-buffered saline containing 0.05\% Tween-20, $10 \mathrm{mmol} / \mathrm{l}$ Tris- $\mathrm{HCl} \mathrm{pH} 7.5$ and $150 \mathrm{mmol} / \mathrm{l} \mathrm{NaCl}$, and then incubated with the appropriate primary antibodies overnight at $4^{\circ} \mathrm{C}$. Horseradish peroxidase-conjugated anti-goat IgG was used as the secondary antibody, and the protein bands were detected using the enhanced chemiluminescence method. The relative protein levels were normalized to $\beta$-actin and expressed as percentages of the control. The membrane was incubated for $30 \mathrm{~min}$ at $50^{\circ} \mathrm{C}$ in buffer that contained $2 \%$ SDS, $62.5 \mathrm{mmol} / 1$ Tris (pH 6.7) and $100 \mathrm{mmol} / 1$ 2-mercaptoethanol. The membrane was then washed and incubated with the other primary antibody.

Chromatin immunoprecipitation (ChIP) assay. ChIP assays were performed using a ChIP Assay kit (Beyotime) according to the manufacturer's instructions. In brief, SiHa cells were fixed by $1 \%$ formaldehyde for $10 \mathrm{~min}$ at $37^{\circ} \mathrm{C}$. Following washing with cold PBS, the cells were lysed in SDS lysis buffer and sonicated to shear the DNA to an average fragment size of $600 \mathrm{bp}$. The lysates were cleared by centrifugation and Ac-Histone H3 (Lys 9/14) antibody was added to the supernatants. Immunoprecipitation from soluble chromatin was conducted overnight at $4^{\circ} \mathrm{C}$. Immune complexes were collected with protein $\mathrm{A}+\mathrm{G}$ agarose/salmon sperm DNA for $60 \mathrm{~min}$ at $4^{\circ} \mathrm{C}$ and then extensively washed. The samples were extracted with elution buffer ( $1 \%$ SDS, $\left.0.1 \mathrm{~mol} / 1 \mathrm{NaHCO}_{3}\right)$ and heated at $65^{\circ} \mathrm{C}$ for $4 \mathrm{~h}$ to reverse cross links. The DNA was purified and used for amplification of the p21 or p27 promoter DNA. The primers used for p21 were: forward, 5'-ACCAACGCAGGCGAGGGACT-3'; and reverse, 5'-CCGG CTCCACAAGGAACTGA-3' (12). The primers used for p27 were: forward, 5'-TGGAGAAGCACTGCAGAGAC-3'; and reverse, 5'-GCGTGTCCTCAGAGTTAGCC-3' (12). The products were separated by agarose gel electrophoresis and visualized by ethidium bromide staining. Each experiment was repeated at least three times.

Statistical analysis. The quantitative variables are presented as means \pm SD. The difference between two groups was assessed using an independent t-test. The differences among $\geq 3$ groups were compared using one-way ANOVA. $\mathrm{P}<0.05$ was considered to be statistically significant. 
A

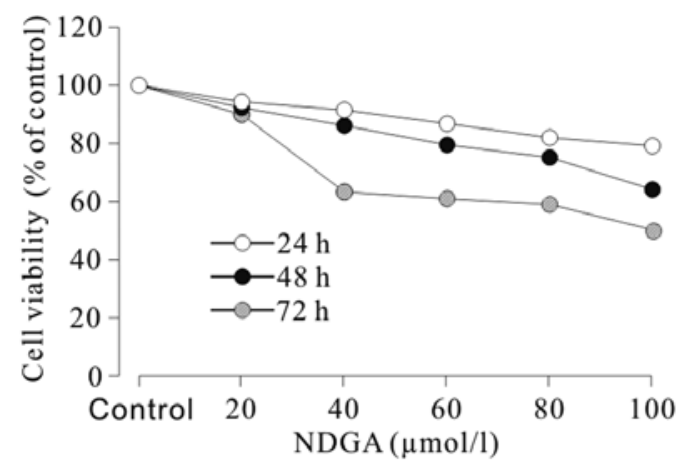

C

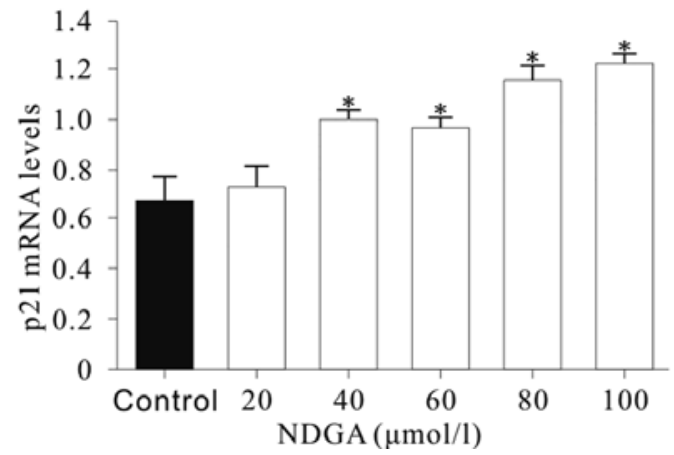

B
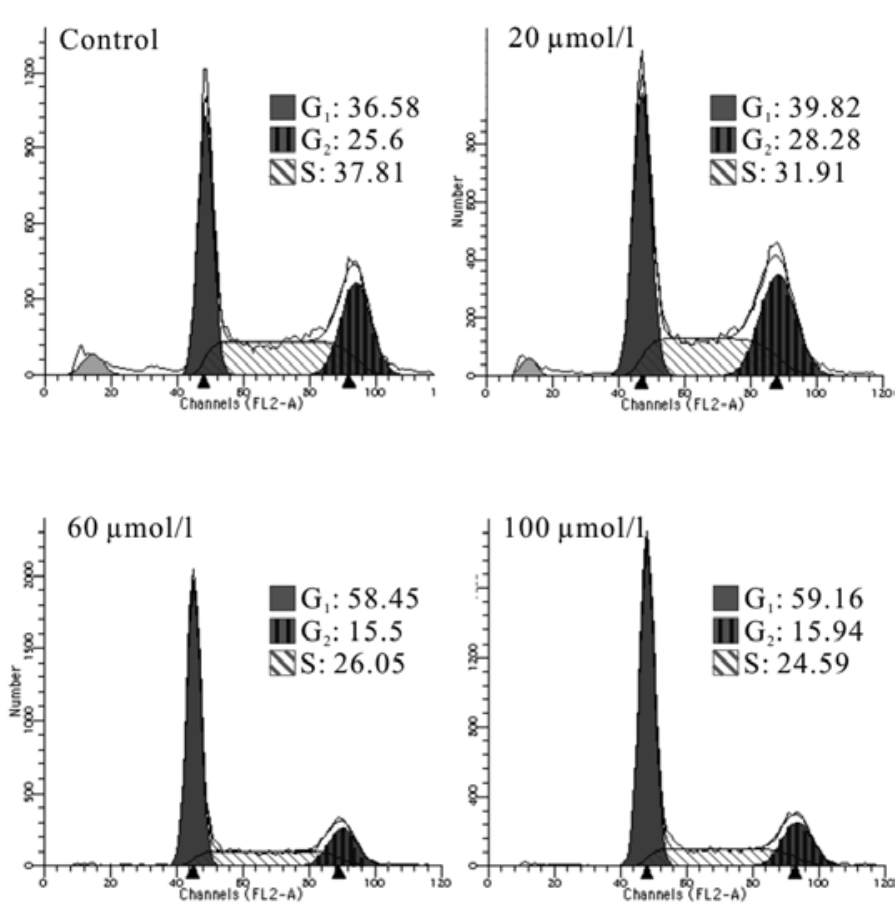

Figure 1. (A) Effects of NDGA on the growth of SiHa cells by MTT assay. (B) Effects of NDGA on the cell cycle of SiHa cells by flow cytometry. (C) NDGA up-regulated the mRNA levels of p21 by RT-PCR. The relative levels of mRNA normalized with GAPDH are shown. ${ }^{*}<0.05$, relative to control.

\section{Results}

NDGA inhibited SiHa cell growth and induced cell cycle arrest at $G_{1}$ phase. The treatment of SiHa cells with various concentrations of NDGA for 24-72 h resulted in cell growth inhibition in a dose- and time-dependent manner (Fig. 1A). A cell cycle assay was performed and it was found that cell cycle progression of SiHa cells was significantly inhibited at the $G_{1}$ phase. As shown in Fig. $1 B$, the SiHa cells showed a higher proportion of cells at the $\mathrm{G}_{1}$ phase and a decrease in the proportion of cells at the $\mathrm{G}_{2}$ phase, compared to the control cells. Cell cycle distribution analysis showed that the increase in $\mathrm{G}_{1}$-phase cells observed in $\mathrm{SiHa}$ was significant $(\mathrm{P}<0.05)$ and the induction of cell cycle arrest was dose-dependent. These results demonstrated that NDGA substantially inhibited the proliferation of $\mathrm{SiHa}$ cells and induced $\mathrm{G}_{1}$ phase arrest in vitro.

NDGA induced cell cycle arrest by up-regulating p21. To determine the mechanisms of NDGA-induced cell cycle arrest, the effect of NDGA on the expression of p21, a key mediator of $G_{1} / S$ transition, was examined. It was found that NDGA treatment for $72 \mathrm{~h}$ significantly increased the levels of p21 mRNA (Fig. 1C) by up to nearly 2-fold.

NDGA induced accumulation of acetylated histone H3. The level of histone H3 acetylation was determined at Lys 9 and 14 in SiHa cells treated with NDGA. Nucleic proteins were isolated from cells treated with NDGA $(80 \mu \mathrm{mol} / \mathrm{l})$ for $72 \mathrm{~h}$. Cells were treated with histone deacetylase inhibitor (HDACi) trichostatin A (TSA) (300 nmol/l) as a positive control. Western blot analysis showed that prior to incubation with
NDGA, the level of acetylated histone H3 in SiHa cell was low (Fig. 2A). Incubation with NDGA for $72 \mathrm{~h}$ resulted in the accumulation of acetylated histone $\mathrm{H} 3$.

The effect of NDGA on the acetylation of histone $\mathrm{H} 3$ associated with the p21 gene promoter was examined by ChIP. Chromatin fragments from cells cultured with and without NDGA $(80 \mu \mathrm{mol} / \mathrm{l})$ for $72 \mathrm{~h}$ were immunoprecipitated with an antibody against acetylated histone $\mathrm{H} 3$ at Lys 9 and Lys 14. DNA from the immunoprecipitated DNA-protein complex was isolated. From this DNA, a 324-bp fragment of the p21 promoter region was amplified. In the control, the acetylated histone $\mathrm{H} 3$ was nearly undetectable. After treatment with NDGA, we observed a significant increase in acetylated histone $\mathrm{H} 3$ within $\mathrm{p} 21$ promoter (Fig. 2B).

NDGA down-regulated silencing mediator for retinoid and thyroid hormone receptors (SMRT) level. To determine the mechanism by which NDGA induced histone H3 acetylation, the effect of NDGA on SMRT transcription was detected. The results showed that NDGA inhibited the SMRT mRNA level in a dose-dependent manner (Fig. 2C).

NDGA had no effect on the acetylation of histones $\mathrm{H} 3$ in chromatin associated with p27 gene. To determine whether this effect was selective for a limited number of genes, the level of histone $\mathrm{H} 3$ acetylation in the p27 gene was examined. The expression of p27 mRNA increased no more than doubled, while the $\mathrm{p} 27$ protein level up-regulated significantly (Fig. 3A and B). No change in the levels of histone $\mathrm{H} 3$ acetylation was detected following treatment with NDGA (Fig. 3C). The results suggest that the NDGA-induced changes in histone acetylation were localized to specific areas of the chromatin. 
A

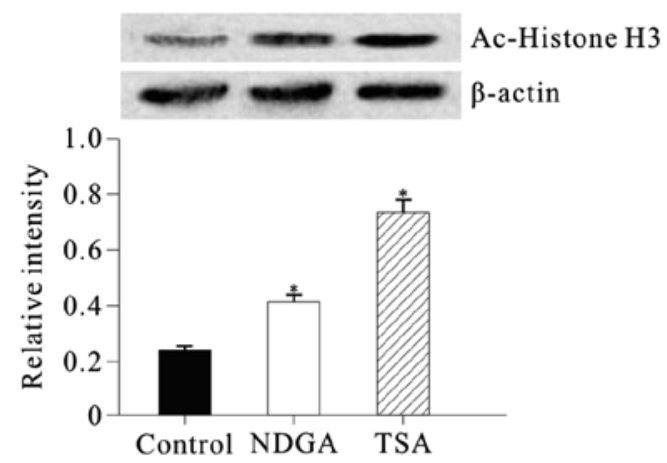

C
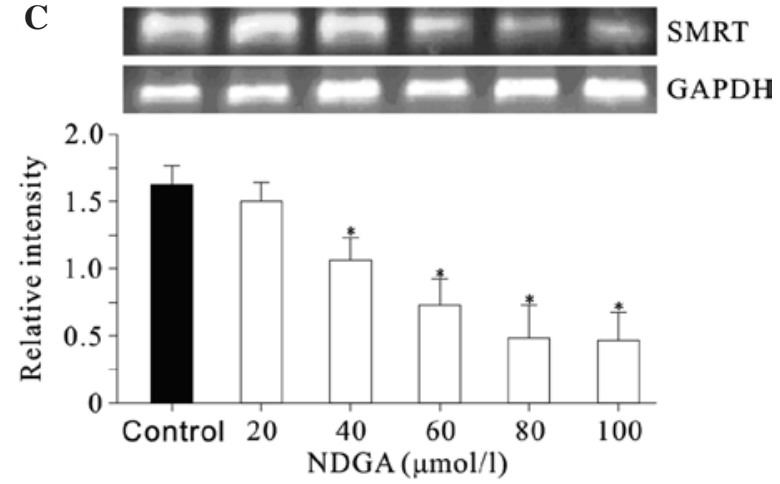

B

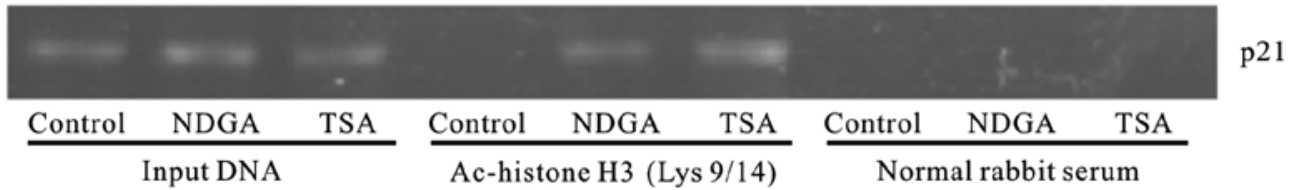

Figure 2. NDGA clearly increased the acetylation levels of (A) global histone H3 and (B) histone H3 associated with p21 promoter in SiHa cells. (A) Protein levels of acetylated histone H3 (Lys 9/14) were measured by Western blotting. The relative levels of acetylated histone H3 were normalized with $\beta$-actin. (B) Acetylation level of histone H3 (Lys 9/14) associated with p21 promoter was measured by ChIP. (C) NDGA inhibited SMRT expression by RT-PCR. $\mathrm{SiHa}$ cells were treated with various NDGA concentrations for $72 \mathrm{~h}$. The relative levels of SMRT mRNA were normalized with GAPDH. * $<0.05$, relative to control.

A

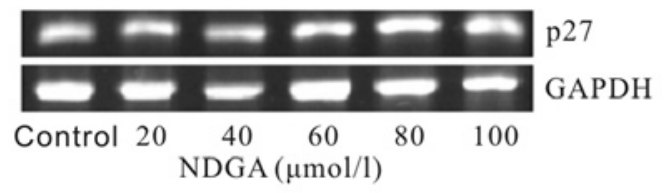

B

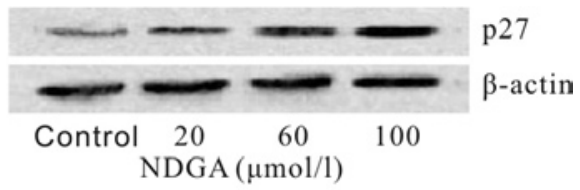

C

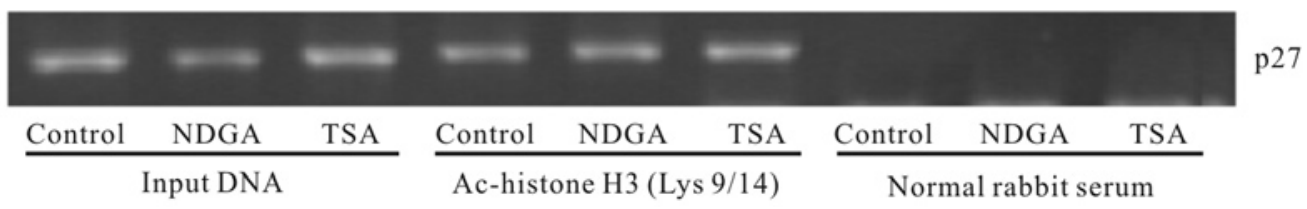

Figure 3. Effects of NDGA on p27 expression. SiHa cells were treated with various NDGA concentrations for $72 \mathrm{~h}$. (A) Effect of NDGA on the expression of p27 mRNA by RT-PCR. (B) Effect of NDGA on the expression of p27 protein by Western blotting. (C) NDGA had no effect on histone H3 acetylation associated with the p27 gene. SiHa cells were treated with $80 \mu \mathrm{mol} / 1$ NDGA for $72 \mathrm{~h}$. TSA served as a positive control. The acetylation level of histone H3 associated with the p27 promoter was measured by ChIP.

A

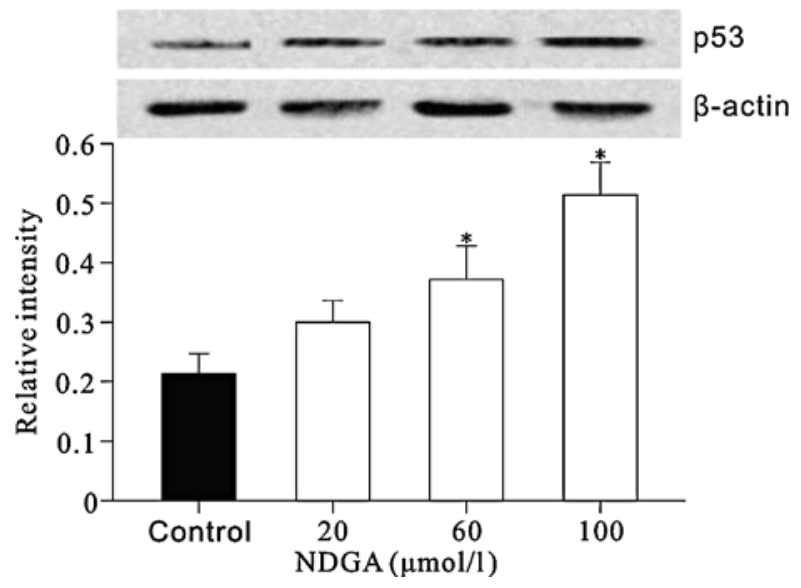

B
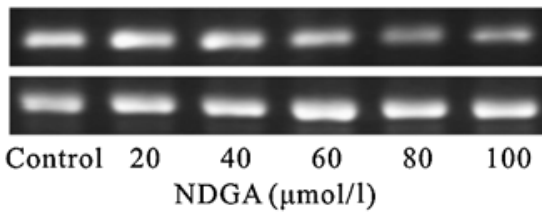

HPV-16 E6

GAPDH

C

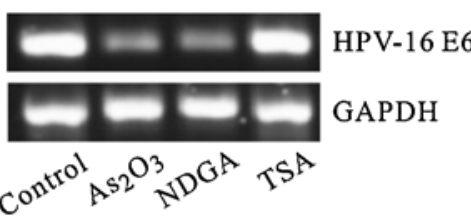

Figure 4. Effects of NDGA treatment on the p53 protein levels and HPV-16 E6 mRNA levels. (A) NDGA increased the p53 protein levels in a dose-dependent manner. SiHa cells were treated with increasing amounts of NDGA for $72 \mathrm{~h}$. p53 expression was examined by Western blotting. The relative levels of the p53 protein were normalized with $\beta$-actin. ${ }^{*} \mathrm{P}<0.05$, relative to control. (B and C) NDGA inhibited the mRNA level of HPV-16 E6 by RT-PCR. 
NDGA restored the protein level of p53 by inhibiting HPV16 E6 expression. The effect of NDGA on the protein level of p53, a tumor suppressor which is also a critical regulator of p21 transcription, was detected. The results showed that NDGA elevated the p53 protein level in a dose-dependent manner (Fig. 4A). The effect of NDGA and TSA on the transcription of HPV16 E6, which induces degradation of p53 was also investigated. $\mathrm{As}_{2} \mathrm{O}_{3}$ was used as a positive control, as it inhibits the expression of HPV16 E6/E7 (16). The results showed that NDGA significantly inhibited the HPV16 E6 mRNA level in a dose-dependent manner (Fig. 4B and C), whereas TSA had no such effect.

\section{Discussion}

NDGA and its derivatives are potentially useful drugs due to their significant inhibitory effects on various types of cancer. However, detailed mechanisms that underlie their anti-cancer roles remain unclear. For this reason, we studied the effect of NDGA on the growth of cervical cancer SiHa cells and its mechanism. We found that NDGA treatment significantly inhibited the growth of SiHa cells and induced cell cycle arrest at the $G_{1}$ phase, which may be a result of the upregulation of $\mathrm{p} 21$, a key mediator of $\mathrm{G}_{1} / \mathrm{S}$ transition. Based on these observations, we studied the effect of NDGA on the p53 protein level and histone $\mathrm{H} 3$ acetylation, two key factors for p21 transcription (10).

In cervical cancer cells, HPV E6 abrogates p53 function (5) and the restoration of p53 activity in SiHa cells increases p21 mRNA $(14,17)$. As with 3-O-methyl-NDGA, a derivative of NDGA (1), we found that NDGA stabilizes p53 protein by suppressing HPV-16 E6 expression. p53 forms a complex with Sp1 and simultaneously dissociates HDAC1 from the $\mathrm{C}$ terminus of $\mathrm{Sp1}$, which, in turn, induces p21 expression (18). Moreover, since HPV E6 and E7 are expressed as bicistronic mRNA, the restoration of $\mathrm{p} 53$ function may be a result of down-regulated HPV E7, the silencing of which decreases histone deacetylase SIRT1 in SiHa cells (19). Reciprocal regulation occurs between SIRT1 and p53 in which SIRT1 binds and de-acetylates activated p53 (20), whereas activated p53 down-regulates SIRT1 translation via miR-34a (21).

For the first time, we found that NDGA promoted the acetylation of histone $\mathrm{H} 3$ in total and p21 gene-associated chromatin, with the latter effect being gene selective, since NDGA has no impact on the p27 gene. However, NDGA promoted the levels of p27 mRNA and particularly that of p27 protein, which, together with p21 and p53, contribute to NDGA-induced cell cycle arrest. It is already established that acetylation at $\mathrm{K} 9$ and $\mathrm{K} 14$ of histone $\mathrm{H} 3$ is associated with the relaxation of chromatin for transcription (22), whereas the acetylation levels at these sites were very low in the SiHa cells $(19,23)$. Although wild-type p53 does not induce acetylation at $\mathrm{K} 9$ and $\mathrm{K} 14$ of histone $\mathrm{H} 3$ (24), it was reported that the presence of p53 likely inhibits K9 deacetylation and facilitates $\mathrm{K} 14$ acetylation in response to UV irradiation (23). Therefore, other mechanisms exist by which NDGA induces histone $\mathrm{H} 3$ acetylation.

The histone acetylation state is affected by the balance between histone deacetylases (HDACs) and histone acetyl transferases (HATs), both of which have various members
(25). Of the numerous HATs that exist, p300 plays a crucial role in the regulation of p21 expression (26). However, in $\mathrm{SiHa}$ cells p300 loses function for mutation (27). A review of the literature showed that HDAC3-HDAC4-N-CoR/SMRT is a complex that plays a critical role in the regulation of histone acetylation associated with the p21 promoter, as HDAC4 or SMRT down-regulation results in increased histone $\mathrm{H} 3$ acetylation at the proximal p21 promoter (28). Our preliminary result proved that NDGA significantly down-regulated SMRT transcription. However, whether NDGA affects other components of this complex remains to be determined.

In conclusion, our results suggest that NDGA induces p21 transcription by selectively elevating histone $\mathrm{H} 3$ acetylation associated with p21 gene and p53 protein levels via inhibition of HPV-16 E6 expression.

\section{Acknowledgements}

This study was supported by the Scientific Research Foundation of the Graduate School of Southeast University, P.R. China (No. YBJJ0915).

\section{References}

1. Allen KL, Tschantz DR, Awad KS, Lynch WP and DeLucia AL: A plant lignan, 3'-O-methyl-nordihydroguaiaretic acid, suppresses papillomavirus E6 protein function, stabilizes p53 protein, and induces apoptosis in cervical tumor cells. Mol Carcinog 46: 564-575, 2007.

2. Meyer GE, Chesler L, Liu D, Gable K, Maddux BA, Goldenberg DD, Youngren JF, Goldfine ID, Weiss WA, Matthay KK and Rosenthal SM: Nordihydroguaiaretic acid inhibits insulin-like growth factor signaling, growth, and survival in human neuroblastoma cells. J Cell Biochem 102: 1529-1541, 2007.

3. Meyers RO, Lambert JD, Hajicek N, Pourpak A, Kalaitzis JA and Dorr RT: Synthesis, characterization, and anti-melanoma activity of tetra-O-substituted analogs of nordihydroguaiaretic acid. Bioorg Med Chem Lett 19: 4752-4755, 2009.

4. Zur Hausen H: Papillomavirus infections - a major cause of human cancers. Biochim Biophys Acta 1288: F55-F78, 1996.

5. Narisawa-Saito M and Kiyono T: Basic mechanisms of high-risk human papillomavirus-induced carcinogenesis: roles of E6 and E7 proteins. Cancer Sci 98: 1505-1511, 2007.

6. Zhao J,Zhao Y, Chen W,Li YM and Bian XW: The differentiationinducing effect of Nordy on HPV-16 subgenes-immortalized human endocervical cells H8. Anticancer Drugs 19: 713-719, 2008.

7. Bahnassy AA, Zekri AR, Alam El-Din HM, Aboubakr AA, Kamel K, El-Sabah MT and Mokhtar NM: The role of cyclins and cyclins inhibitors in the multistep process of HPV-associated cervical carcinoma. J Egypt Natl Canc Inst 18: 292-302, 2006.

8. Tsao YP, Huang SJ, Chang JL, Hsieh JT, Pong RC and Chen SL: Adenovirus-mediated p21(WAF1/SDII/CIP1) gene transfer induces apoptosis of human cervical cancer cell lines. J Virol 73: 4983-4990, 1999.

9. Hirano K, Hirano M, Zeng Y, Nishimura J, Hara K, Muta K, Nawata $\mathrm{H}$ and Kanaide $\mathrm{H}$ : Cloning and functional expression of a degradation-resistant novel isoform of p27Kip1. Biochem J 353: 51-57, 2001.

10. Abbas T and Dutta A: p21 in cancer: intricate networks and multiple activities. Nat Rev Cancer 9: 400-414, 2009.

11. Chen YX, Fang JY, Lu R and Qiu DK: Expression of p21(WAF1) is related to acetylation of histone $\mathrm{H} 3$ in total chromatin in human colorectal cancer. World J Gastroenterol 13: 2209-2213, 2007.

12. Richon VM, Sandhoff TW, Rifkind RA and Marks PA: Histone deacetylase inhibitor selectively induces p21WAF1 expression and gene-associated histone acetylation. Proc Natl Acad Sci USA 97: 10014-10019, 2000. 
13. Giannoudis A and Herrington CS: Differential expression of p53 and p21 in low grade cervical squamous intraepithelial lesions infected with low, intermediate, and high risk human papillomaviruses. Cancer 89: 1300-1307, 2000.

14. Hietanen S, Lain S, Krausz E, Blattner C and Lane DP: Activation of p53 in cervical carcinoma cells by small molecules. Proc Nat Acad Sci USA 97: 8501-8506, 2000.

15. De-Castro Arce J, Göckel-Krzikalla E and Rösl F: Retinoic acid receptor beta silences human papillomavirus-18 oncogene expression by induction of de novo methylation and heterochromatinization of the viral control region. J Biol Chem 282: 28520-28529, 2007.

16. Deng Y, Lin C, Zheng J, Fu M, Liang X, Chen J, Xiao P and Wu M: Overexpression of Bcl-2 partly inhibits apoptosis of human cervical cancer $\mathrm{SiHa}$ cells induced by arsenic trioxide. Chin Med J (In English) 113: 84-88, 2000.

17. Yoshinouchi M, Yamada T, Kizaki M, Fen J, Koseki T, Ikeda Y, Nishihara $\mathrm{T}$ and Yamato $\mathrm{K}$ : In vitro and in vivo growth suppression of human papillomavirus 16-positive cervical cancer cells by E6 siRNA. Mol Ther 8: 762-768, 2003.

18. Lagger G, Doetzlhofer A, Schuettengruber B, Haidweger E, Simboeck E, Tischler J, Chiocca S, Suske G, Rotheneder H, Wintersberger E and Seiser C: The tumor suppressor p53 and histone deacetylase 1 are antagonistic regulators of the cyclindependent kinase inhibitor p21/WAF1/CIP1 gene. Mol Cell Biol 23: 2669-2679, 2003.

19. Allison SJ, Jiang $M$ and Milner J: Oncogenic viral protein HPV E7 up-regulates the SIRT1 longevity protein in human cervical cancer cells. Aging 1: 316-327, 2009.
20. Vaziri H, Dessain SK, Ng Eaton E, Imai SI, Frye RA, Pandita TK, Guarente L and Weinberg RA: hSIR2(SIRT1) functions as an NAD-dependent p53 deacetylase. Cell 107: 149-159, 2001.

21. Yamakuchi M, Ferlito M and Lowenstein CJ: miR-34a repression of SIRT1 regulates apoptosis. Proc Natl Acad Sci USA 105: 13421-13426, 2008.

22. Jenuwein $\mathrm{T}$ and Allis $\mathrm{CD}$ : Translating the histone code. Science 293: 1074-1080, 2001.

23. Allison SJ and Milner J: Loss of p53 has site-specific effects on histone H3 modification, including serine 10 phosphorylation important for maintenance of ploidy. Cancer Res 63: 6674-6679, 2003.

24. Warnock LJ, Adamson R, Lynch CJ and Milner J: Crosstalk between site-specific modifications on p53 and histone H3. Oncogene 27: 1639-1644, 2008.

25. Eberharter A and Becker PB: Histone acetylation: a switch between repressive and permissive chromatin. Second in review series on chromatin dynamics. EMBO Rep 3: 224-229, 2002.

26. Xiao H, Hasegawa T and Isobe K: p300 collaborates with Sp1 and $\mathrm{Sp} 3$ in $\mathrm{p} 21$ (waf $1 / \mathrm{cip} 1$ ) promoter activation induced by histone deacetylase inhibitor. J Biol Chem 275: 1371-1376, 2000.

27. Ohshima T, Suganuma T and Ikeda M: A novel mutation lacking the bromodomain of the transcriptional coactivator p300 in the $\mathrm{SiHa}$ cervical carcinoma cell line. Biochem Biophys Res Commun 281: 569-575, 2001.

28. Wilson AJ, Byun DS, Nasser S, Murray LB, Ayyanar K, Arango D, Figueroa M, Melnick A, Kao GD, Augenlicht LH and Mariadason JM: HDAC4 promotes growth of colon cancer cells via repression of p21. Mol Biol Cell 19: 4062-4075, 2008. 